\title{
The relationship between dissolved organic matter (DOM) and arsenic- release at two, hydrogeologically- contrasting, aquifers in Kandal Province, Cambodia
}

OLIVER MOORE, NAJI BASSIL, LAURA RICHARDS, BART VAN DONGEN, DAVID POLYA AND JONATHAN RICHARD LLOYD

University of Manchester

Presenting Author: oliver.moore@manchester.ac.uk

The contamination of drinking water sources with naturallyoccurring arsenic impacts tens of millions of people globally [1]. In the highly-reducing, alluvial and deltaic aquifers of South East Asia, microbial-mediated reductive-dissolution of arsenicbearing iron (oxy)hydroxides is thought to be the primary cause of arsenic-release into the aqueous-phase [2]. Organic matter $(\mathrm{OM})$ plays a key part in this process, as a source of bioavailable electron donors and electron shuttles [3]; and in competitive sorption and complexation reactions [4].

Extensive characterisation of dissolved organic matter (DOM) was carried out on groundwaters sampled from eight 18 metre deep wells, drilled at two hydrogeologically-contrasting sites (a clay-dominated and a sand-dominated site, called "Clay Site" and "Sand Site", respectively) southeast of Phnom Penh, Kandal Province, Cambodia. The hydrogeology of these sites has been characterised extensively in previous studies [5].

Excitation emission matrix (EEM) analysis showed that Clay Site DOM is characterised by a higher proportion of microbialderived compounds (e.g. tryptophan-like) and of higher biolability; whereas Sand Site DOM is characterised by higher proportions of terrestrial-derived compounds (e.g. fulvic acidlike) and a lower bio-lability. These results are comparable with previous EEM studies of the DOM of the region [6]. Further analysis of the DOM from these sites (e.g. by Fourier TransformIon Cyclotron Resonance Mass Spectrometry - FTICR-MS) is planned in order to investigate the relationship between DOM molecular composition, bioavailability and arsenic-release. These findings will provide further insights into the role of $\mathrm{OM}$ in arsenic-release by reductive-dissolution, and help target further studies.

\section{References:}

[1] Polya \& Middleton. (2017). in Best Practice Guide on the Control of Arsenic in Drinking Water 16, 1-23.; [2] Islam et al. (2004). Nature 430, 68-71.; [3] Rowland et al. (2007). Geobiology 5, 281-292.; [4] Mladenov et al. (2015). Environ. Sci. Technol. 49, 10815-10824.; [5] Richards et al. (2017). Sci. Total Environ. 590-591, 540-553.; [6] Richards et al. (2019) Geosci. Front. 10, 1653-1667. 